\title{
ARTICLE OPEN Surface degradation mechanisms in precipitation-hardened high-entropy alloys
}

\author{
Aditya V. Ayyagari ${ }^{1,3}$, Bharat Gwalani ${ }^{1,2}$, Saideep Muskeri ${ }^{1}$, Sundeep Mukherjee ${ }^{1,2}$ and Rajarshi Banerjee ${ }^{1,2}$
}

Design of high-entropy alloys with complex microstructures presents a unique opportunity to combine the best of solid solution strengthening and precipitation hardening. These alloys are potentially disruptive for several high-performance applications including aerospace, oil and gas, nuclear industry, and next-generation tribology. This study presents the thermo-mechanical treatment, microstructural evolution, and surface degradation resistance in precipitation hardenable $\mathrm{Al}_{0.3} \mathrm{Cu}_{0.3} \mathrm{Ti}_{0.2} \mathrm{CoCrFeNi}_{\mathrm{igh}}$ entropy alloy. The heat-treated alloy consisted of fine precipitates of $L 1_{2}$ and $L 2_{1}$, strengthening the face-centered cubic solid solution matrix. Potentiodynamic polarization showed nano-galvanic coupling between the intermetallic particles and the matrix. Phase-specific nano-indentation showed that hard intermetallic particles caused three-body wear and higher friction values during sliding wear. The microstructure was correlated with processing conditions and resulting surface degradation resistance using transmission electron microscopy imaging and analysis.

npj Materials Degradation (2018)2:33; doi:10.1038/s41529-018-0054-1

\section{INTRODUCTION}

High-entropy alloys (HEAs) represent a new paradigm in materials development in terms of simultaneously achieving ultra-high strength, good formability, and excellent fracture toughness. ${ }^{1}$ Several of these alloys show superior mechanical properties at elevated $^{2-4}$ as well as cryogenic temperatures, ${ }^{1}$ possess superior resistance to irradiation damage, ${ }^{5,6}$ and surface oxidation. ${ }^{7-9}$ In addition to the superior bulk properties, they possess exceptional tolerance to surface damage via wear, ${ }^{10-16}$ corrosion, ${ }^{2,17-21}$ erosion, ${ }^{22,23}$ and tribocorrosion. ${ }^{24}$ In addition to the vast majority of HEAs developed till date that are single-phase solid solutions, the underlying thermodynamic principles have been expanded to formulate multi-phase HEAs such as eutectic HEAs, ${ }^{25-28}$ particlereinforced alloys, ${ }^{29}$ complex concentrated microstructures, ${ }^{30}$ and super alloy architecture strengthened with complex ordered precipitates. $^{31-33}$ Preliminary studies demonstrated that several of these alloys have high strength-toughness combination and superior application worthiness for advanced aerospace applications.

This study presents a new $\mathrm{HEA}, \mathrm{Al}_{0.3} \mathrm{Cu}_{0.3} \mathrm{Ti}_{0.2} \mathrm{CoCrFeNi}$, where $\mathrm{Cu}$-rich clusters first precipitate out from the matrix and act as sites for heterogenous nucleation for subsequent precipitation. Al and $\mathrm{Ti}$ promote the formation of nanometer-scale $\mathrm{L} 1_{2}$ phase on the $\mathrm{Cu}$ clusters that contribute to the strengthening effects. The alloy was cast and subsequently thermo-mechanically processed to tailor the microstructure for superior surface degradation resistance. The heat treatment generated fine secondary phase particles that improved strength in addition to enhancing surface degradation resistance. The corrosion and wear behavior were evaluated after thermo-mechanical treatment and precipitation of nano-scale secondary phases. Phase-specific hardness and modulus was measured using nano-indentation to elucidate bulk wear and friction behavior. Open-circuit potential (OCP) measurement tests followed by potentiodynamic polarization tests were carried out to understand the passivation mechanism and accelerated corrosion behavior, respectively. Scanning and transmission electron microscopy (TEM) were utilized to explain the overall contribution of precipitated phases on the surface properties.

\section{RESULTS AND DISCUSSION}

The as-cast alloy was homogenized at $1150^{\circ} \mathrm{C}$ for $1 \mathrm{~h}$ followed by cross-rolling (CR) at room temperature for $70 \%$ reduction in thickness. CR has been reported to effectively break the as-cast microstructure, randomize rolling texture, and produce fine equiaxed grains. ${ }^{34,35}$ The $C R$ alloy was then subjected to hightemperature annealing at $1150^{\circ} \mathrm{C}$ for $5 \mathrm{~min}$ to recrystallize the grains (referred to as CR-R). The recrystallized samples were subjected to two different aging treatments, namely, $800^{\circ} \mathrm{C}$ for $30 \mathrm{~min}$ (referred to as CR-R-800) and $600^{\circ} \mathrm{C}$ for $150 \mathrm{~h}$ (referred to as CR-R-600). The SEM (scanning electron microscopy) micrographs recorded using back-scattered electron detector from these conditions are shown in Fig. 1a-c, respectively. All three microstructures showed recrystallized grains and a grain boundary phase homogenously distributed in the entire sample. Results of phase analysis carried out using electron back-scattered diffraction (EBSD) orientation microscopy are shown in Fig. 2a-h. Figure $2 a$, $b$ show the inverse pole figure map (IPF) and the phase map, respectively, from $C R-R$ condition. Figure $2 b$ shows the facecentered cubic (fcc) matrix grains in red, while a continuous network of green dots decorating grain boundaries has been

\footnotetext{
${ }^{1}$ Department of Materials Science and Engineering, University of North Texas, Denton, TX 76207, USA and ${ }^{2}$ Advanced Materials and Manufacturing Processes Institute, University of North Texas Denton, Denton, TX 76207, USA

Correspondence: Rajarshi Banerjee (rajarshi.banerjee@unt.edu)

${ }^{3}$ Present address: Argonne National Laboratory, Center for Nanoscale Materials, Lemont, IL 60439, USA

These authors contributed equally: Aditya V. Ayyagari, Bharat Gwalani.
}

Received: 11 July 2018 Revised: 31 August 2018 Accepted: 11 September 2018

Published online: 02 October 2018 

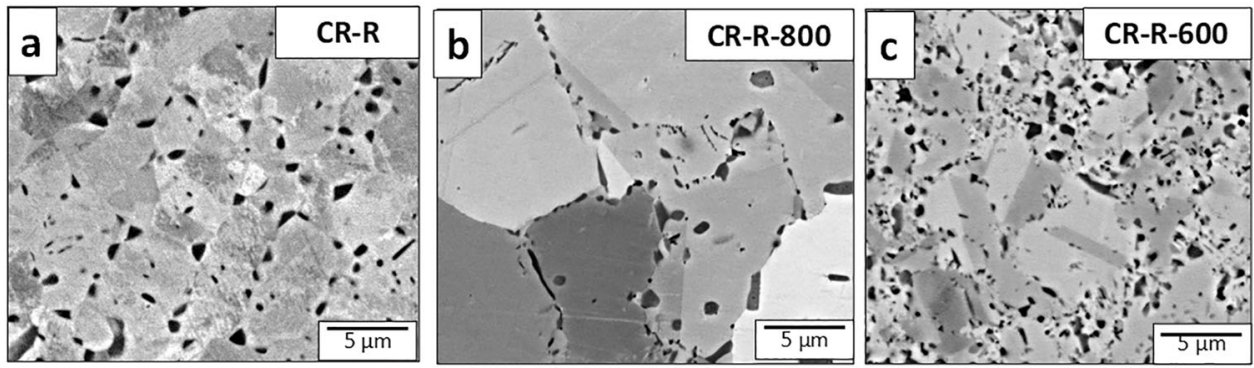

Fig. 1 SEM microscopy: a Alloy recrystallized at $1150^{\circ} \mathrm{C}$ for $5 \mathrm{~min}(\mathrm{CR}-\mathrm{R})$ showing fully recrystallized grain structure, with some grains showing annealing twins. b Alloy processed at $800^{\circ} \mathrm{C}$ for $30 \mathrm{~min}$ (CR-R-800) with a small fraction of secondary phase nucleating on the grain boundary. c Alloy recrystallized at $600^{\circ} \mathrm{C}$ for $150 \mathrm{~h}(\mathrm{CR}-\mathrm{R}-600)$ having a refined grain structure and continuous secondary phase along the grain boundary
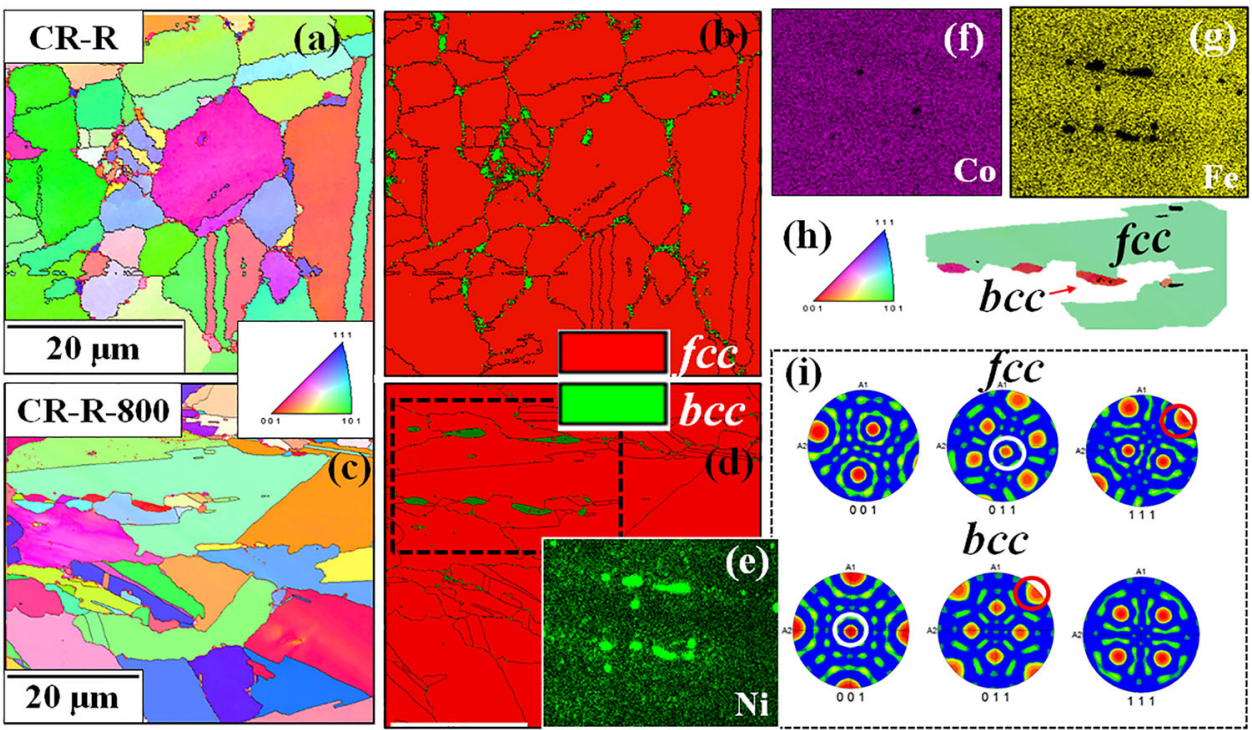

Fig. 2 SEM orientation image microscopy: a Inverse pole figure (IPF) map showing the grain orientation on CR-R sample. b Phase map color coded with red on the fcc matrix grains, while a continuous network of green dots decorating grain boundaries is indexed to be bcc phase. $\mathrm{c}$ IPF on the CR-R-800 sample. d Phase map delineating the fcc and bcc phase distribution. e-g EDS maps of Ni, Co, and Fe showing the elemental partitioning. $\mathbf{h}, \mathbf{i}$ IPF and PF showing the orientation relationship between the fcc matrix and bcc phase on the grain boundary

indexed as a body-centered cubic (bcc) phase. The grain size for the recrystallized alloy was $\sim 10 \mu \mathrm{m}$, whereas it was $\sim 20 \mu \mathrm{m}$ for CR$\mathrm{R}-800$ as seen in Fig. 2c. The bcc grain boundary phase in CR-R-800 appeared to have coarsened due to the second annealing treatment (Fig. 2d). An EDS map of the area highlighted with the dotted rectangle in Fig. $2 d$ revealed that the bcc grain boundary phase was Ni rich as shown in Fig. 2e. Figure $2 \mathrm{f}, \mathrm{g}$ show compositional maps of $\mathrm{Co}$ and $\mathrm{Fe}$, clearly depicting the partitioning trend. The grain boundary phase was observed to be rich in $\mathrm{Ni}$, $\mathrm{Al}$, and $\mathrm{Ti}$, while lean in $\mathrm{Fe}$ and $\mathrm{Cr}$. Co and $\mathrm{Cu}$ were not seen to partition strongly. ${ }^{36}$ The $\mathrm{fcc}$ and bcc phases exhibit an orientation relationship which can be established from the EBSD results. A selected fcc grain with a bcc precipitate decorating the grain boundary is shown in Fig. $2 \mathrm{~h}$. The pole figures corresponding to the phases are shown in Fig. $2 \mathrm{i}$. It is seen that the $\{001\}$ pole of bcc is parallel to the $\{011\}$ pole of the fcc (white circle in Fig. 2i) and the $<011>$ pole of bcc is parallel to the $<111>$ pole of the fcc (red circle in Fig. 2i). This establishes a Nishiyama-Wassermann type of orientation relationship in between the matrix and the grain boundary bcc precipitate. After looking at the grain boundary precipitates in TEM, we found that they are in fact ordered $L 2_{1}$, the details of which are discussed in the next section.

TEM was performed to characterize the constituent phases in the three conditions. The TEM images from the three alloys are shown in Fig. 3a-f. Figure 3a shows the selected area diffraction pattern (SADP) from the $[011]_{\mathrm{fcc}}$ zone axis from the $\mathrm{CR}-\mathrm{R}$ condition. Note that only the fundamental fcc spots are seen in this condition even after long time exposure. The absence of any extra super-lattice spots indicates the lack of ultrafine-scale phases within the matrix. Therefore, it may be concluded that the CR-R condition consists of a single solid solution fcc phase. The SADP from [011] zone axis from the grain boundary phase is shown in Fig. 3b. The precipitates clearly show a bcc-type ordered crystal structure. The presence of $1 / 4,2 / 4,3 / 4\{222\}$ spots in [011] zone axis establish this phase to be an ordered $L 2_{1}$ phase. The existence of extra $((\overline{1} \overline{1})(\overline{111})$ reflections in Fig. $3 \mathrm{~b}$ are inconsistent with B2 ordering, which has a symmetry of $P m \overline{3} \mathrm{~m}$. However, the presence of these reflections is consistent with the $f m \overline{3} m$ symmetry observed for the [110] zone of an ordered L2 ${ }_{1}$ structure (Huesler structure, $f(m \overline{3} m$ ). Moreover, detailed assessment on the grain boundary phases under these conditions revealed the presence of sigma and bcc phases together with the $L 2_{1}$ precipitates. Since the fraction of these grain boundary phases is relatively very low, these phases will not be subsequently discussed in the context of the present paper. The $[011]_{\mathrm{fcc}}$ from both CR-R-600 (Fig. 3c) and CR-R-800 (Fig. 3e) shows the presence of super-lattice spots in $\{001\}$ and $\{011\}$ positions, clearly corresponding to the ordered $L 1_{2}$ phase. Dark field (DF) TEM images, recorded using the $\{001\} L 1_{2}$ spots, as encircled in Fig. 3c, e, from CR-R-600 and CR-R-800 conditions, respectively, are shown in Fig. $3 d$, f. These DF images 

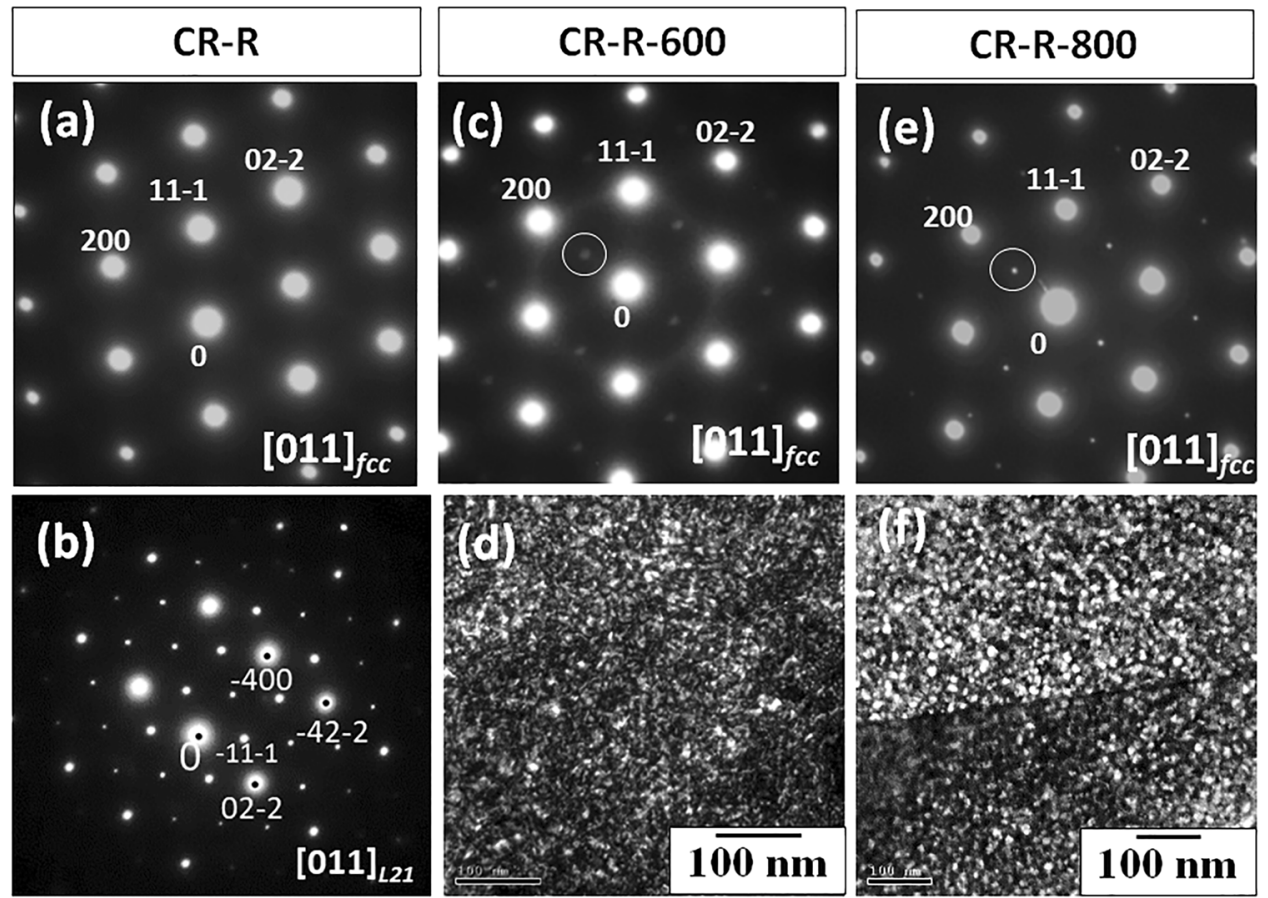

Fig. 3 TEM microscopy: a CR-R condition SADP from the matrix showing zone axis $(Z A)[011]_{\mathrm{fcc}}$ b CR-R condition SADP from the grain boundary precipitate showing $Z A=[011]_{121}$. c CR-R-600 condition SADP from the matrix showing $Z A=[011]_{\mathrm{fcc}}$ the super-lattice spot is encircled. $\mathbf{d}$ CR-R-600 condition DFTEM from the encircled super-lattice spot in (c). e CR-R-800 condition SADP from the matrix showing ZA = $[011]_{\mathrm{fcc}}$, with the super-lattice spot encircled. $\mathbf{f}$ CR-R-800 condition DFTEM from the encircled super-lattice spot in (e)

reveal a homogeneous distribution of highly refined $L 1_{2}$ precipitates within the fcc matrix for both samples. The in-depth microstructural analysis at multiple length scales formed the basis for understanding surface degradation behavior of the alloys.

OCP is the voltage difference measured between the working electrode and the reference electrode when no current flows through the electrolytic cell. The thermodynamics of surface chemical reactions can be understood by the nature and rate of change of OCP when immersed in an electrolyte. The surfaces that possess relatively higher potential and rapidly attain thermodynamic equilibrium with the electrolyte tend to have better corrosion resistance. The OCPs obtained after immersing the alloys in $3.5 \mathrm{wt} \% \mathrm{NaCl}$ solution are shown in Fig. 4a. The solutionized and CR-R-800 attained stable OCP values within $1 \mathrm{ks}$, whereas the CRR-600 sample took significantly longer to attain equilibrium. The stable OCP values of the alloys are summarized in Table 1. The CR$\mathrm{R}$ condition had the noblest corrosion potential followed by CR-R800 and then CR-R-600. Potentiodynamic polarization curves of the three conditions are shown in Fig. 4b. The potentiograms were characterized by a wide anodic branch indicating that a large potential is required to initiate stable pitting on the samples. Pitting potential $\left(E_{\mathrm{pit}}\right)$ is the potential beyond which there is a continuous surge of corrosion current in the system. The current density monotonically increased with applied potential beyond $E_{\text {pit. }}$. Among the three samples, CR-R-600 showed lowest pitting potential, followed by CR-R-800 and CR-R. The observed corrosion current may be attributed to one large pit dissolving rapidly or several small pits growing simultaneously. Therefore, detailed SEM analysis was done for comprehensive understanding of the pitting corrosion behavior as discussed in the subsequent sections. In addition to the prominent pitting event characterized by a large and continuous surge in corrosion current, multiple small current spikes were observed on the anodic branch of CR-R-800 and CR-R600 samples. A magnified view of the anodic branch of the potentiogram between -150 and $100 \mathrm{mV}$ is shown in Fig. 4c. The curve corresponding to the CR-R- 600 condition had multiple small current spikes as compared to the other two alloy conditions. These current spikes correspond to small pitting events at various stages of nucleation, growth, and re-passivation ${ }^{37-40}$ as reported for AlCoCrFeNi HEA systems with complex microstructures. ${ }^{21}$

The corrosion current densities of the alloys calculated as the point of intersection of the slopes of anodic and cathodic branches of the polarization curves are summarized in Table 1. The CR-R condition with lowest corrosion current density had the highest corrosion resistance as compared to the other two processing conditions. The pitting morphology after potentiodynamic polarization tests are shown in Fig. 5. The solutionized sample showed large pits (Fig. 5a) sparsely distributed on the sample surface. A high magnification SEM image of the pit interior shown in Fig. 5b revealed clear grain facets and slip systems that are susceptible to corrosion once protective passive layer is ruptured. High magnification images further revealed that triple junctions were decorated with submicron-sized pits as shown in Fig. 5c, which may be corrosion initiation sites that eventually grew and coalesced. These small pits may explain the corrosion current spikes on the potentiogram of the solutionized alloy (Fig. $5 c)$. The average pit size on the CR-R-800 sample was smaller compared to solutionized condition and the pit number density was higher. Pit morphology on the CR-R- 800 sample is shown in Fig. 5d. Similar to solutionized condition, corrosion may have initiated on the grain boundaries, evidenced by preferential grain boundary etching highlighted in Fig. $5 \mathrm{~d}$. A high magnification image (Fig. 5e) of the pit interior shows bright particles decorating the grain boundaries. These particles on the grain boundaries are most likely $\mathrm{L} 2_{1}$ intermetallic particles (Fig. $2 \mathrm{~g}$ ). Corrosion from $\mathrm{L} 1_{2}$ phases on the surface may explain the short anodic current spikes for the CR-R-800 sample. Besides grain boundary precipitates, squircle-shaped pits on the grain interiors are also seen in Fig. $5 f$. These pits may have formed as a consequence of galvanic corrosion between the intra-granular ordered $\mathrm{L}_{2}$ precipitates and the matrix. The $\mathrm{L} 1_{2}$ particles have a spherical-to-cubic morphology as seen from TEM studies (Fig. 3) that are consistent with the 

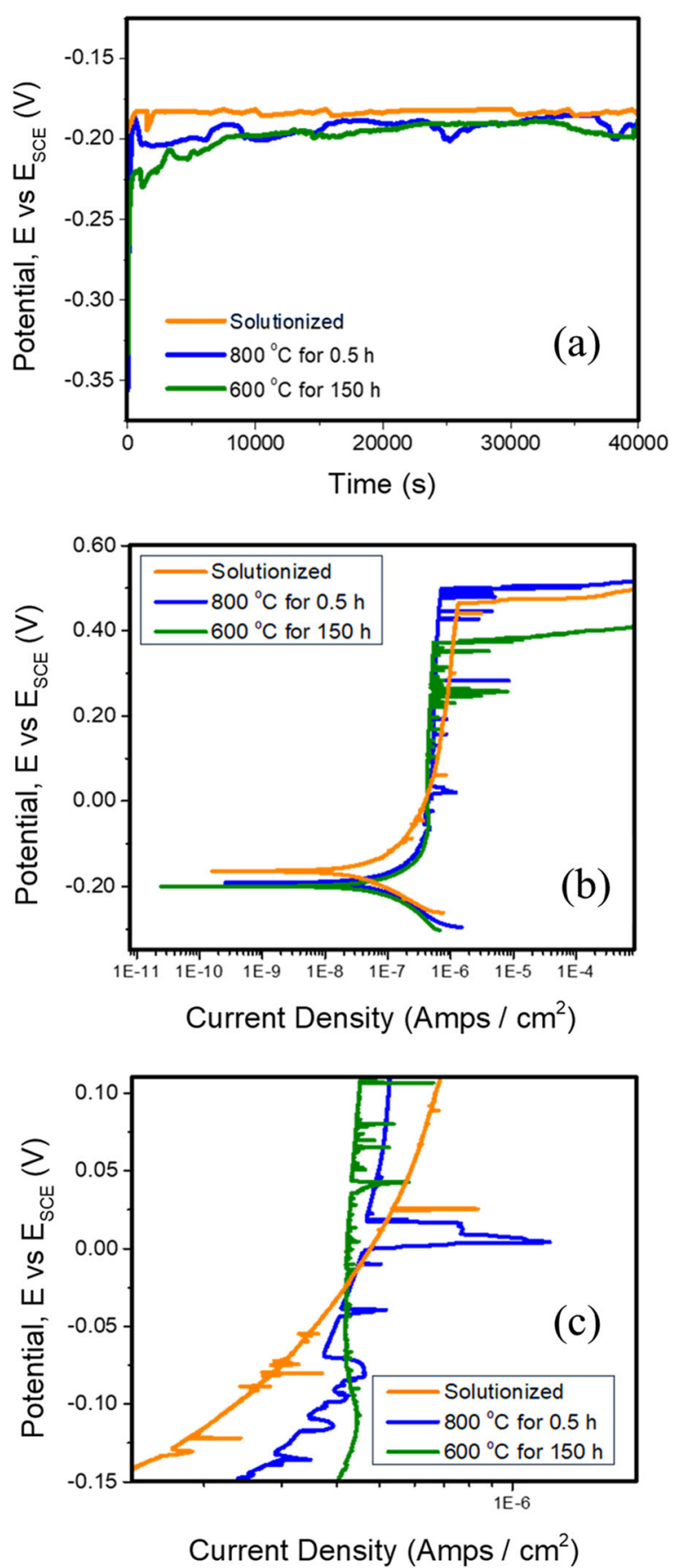

Fig. 4 a Open-circuit potentials for the alloys showing incipient passivation breakdown and re-passivation. b Potentiodynamic polarization curves. c Magnified view of the anodic branch of the polarization curve showing pit instability on the surface of alloys seen as current spikes

pitting morphology. In stark contrast to the morphology seen in CR-R and CR-R-800, the corrosion for CR-R-600 condition was predominantly galvanic coupling between nano-scale precipitates and the matrix. Figure $5 \mathrm{~g}$ shows a low magnification image of the surface with predominant material loss along the grain boundaries. A continuous basket-weave-type pattern of shallow elongated pits were observed inside the grains. A zoomed-in view of a grain boundary triple junction is shown in Fig. 5h. The grain boundary shows three distinct contrasts in back-scattered mode of electron imaging. Using EDS, the areas with dark contrast were

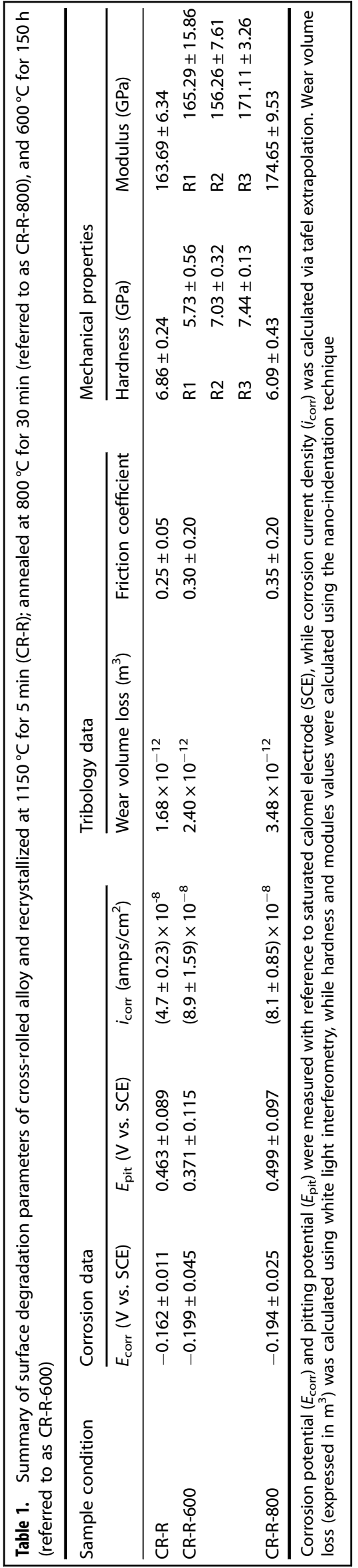



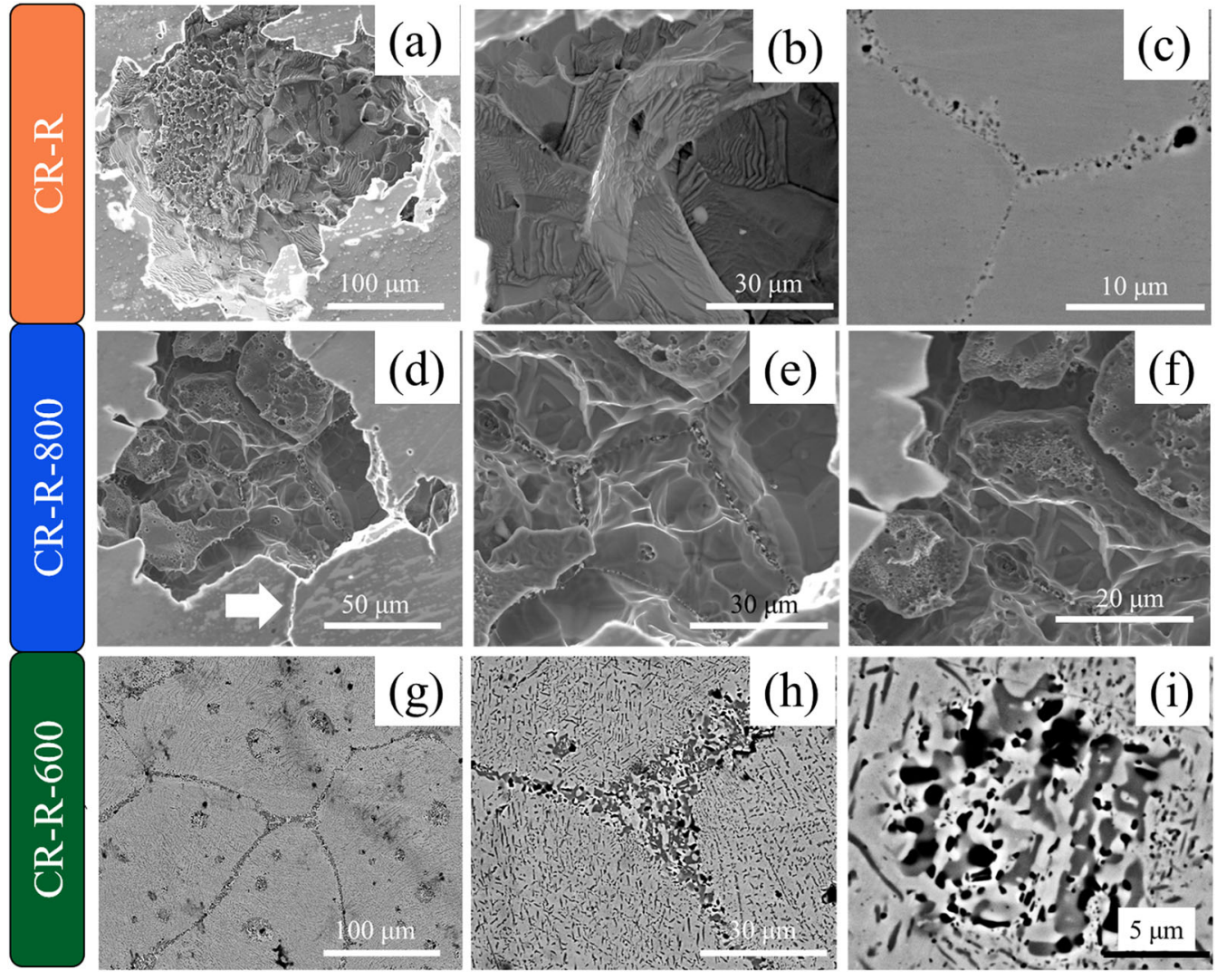

Fig. 5 Corrosion morphologies following potentiodynamic polarization tests: a On the solutionized alloy imaged at low magnification. b Interior of the corroded region showing slip planes. c High magnification image showing very small pitting sites on the grain boundary. $\mathbf{d}$ Pitting morphology on the CR-R-800. e Small bright phases decorating the grain boundaries preferentially corroding and forming micro-pits. $f$ Squircle-shaped pits on the grain interiors possibly left after preferred galvanic corrosion of intermetallic particles. $\mathbf{g}$ Low magnification image of corrosion morphology on the CR-R-600. $\mathbf{h}$ grain boundary corrosion and selective corrosion of secondary phases. $\mathbf{i}$ High magnification image showing complex micro-galvanic interaction between $\mathrm{L} 2_{1}$, and matrix in the alloy

identified as deep pits and the gray to be enriched with $\mathrm{Al} / \mathrm{Ti} / \mathrm{Ni}$ and depleted of $\mathrm{Fe} / \mathrm{Cu} / \mathrm{Cr}$. Figure $5 \mathrm{i}$ shows these features in detail. The short anodic current spikes may be attributed to secondary phases in the respective alloys. ${ }^{37-40}$ The CR-R sample is relatively more homogenous compared to the other two alloy conditions. Since secondary precipitates act as sites for corrosion initiation lower volume fraction of these particles led to lesser number of transient current spikes on the anodic branch of the potentiogram. This was followed by the CR-R-800 sample, where number density and size of precipitates (grain boundary and within grains) were greater than CR-R sample. This resulted in relatively more number of short corrosion spikes compared to the CR-R condition. The CR-R-600 sample showed maximum number of anodic current spikes among the three potentiograms. The current spikes were small at low anodic voltages, but increased in magnitude with the potential sweep up to pitting potential. The small current spikes likely originated from corrosion of finer features, forming the periodic basket-weave pattern with feature size of a few hundred nanometers. The larger current spikes may be attributed to dissolution of larger grain boundary phases (Fig. $5 g-h)$. Therefore, it may be concluded that finer phases resulting in the basketweave corrosion morphology were more susceptible to corrosion, as they formed at lower anodic voltages compared to the grain boundary phases that corroded at higher potentials.

The periodic basket-weave pattern was composed of two distinct features, a circular deep pit along with shallow elongated pits (Fig. 5h). The two distinct corrosion morphologies may be explained based on compositional partitioning of elements within the matrix. An elemental mapping created using CHEMI-STEM technique in energy-dispersive spectroscopy (EDS) (Super-X system) equipped on an FEI-TITAN G2 TEM microscope in the HAADF STEM mode operating at $300 \mathrm{kV}$ is shown in Fig. 6 . The elemental partitioning may be grouped into three regions, continuous matrix (rich in $\mathrm{Fe}, \mathrm{Co}$, and $\mathrm{Cr}$ ), $\mathrm{L}_{2}$, precipitates (rich in $\mathrm{Al}, \mathrm{Ti} \mathrm{Ni}$, and $\mathrm{Cu}$ ), and $\mathrm{Cu}$-rich clusters attached to $\mathrm{L1}_{2}$ precipitates. Ti partitioning was found to be very similar to $\mathrm{Al}$, and hence is omitted from the illustration. The matrix phase has a nominal composition of $\mathrm{Al}_{4.06} \mathrm{Co}_{20.46} \quad \mathrm{Cr}_{18.09} \mathrm{Ni}_{22.36}$ $\mathrm{Fe}_{1922} \mathrm{Ti}_{4.59} \mathrm{Cu}_{11.21}$ (atomic percent), showing enrichment with CoCrNiFe. The $\mathrm{L1}_{2}$ had a nominal composition of $\mathrm{Al}_{12.16} \mathrm{Co}_{16.29} \mathrm{Cr}_{3.68} \mathrm{Ni}_{44.29} \mathrm{Fe}_{5.63} \mathrm{Ti}_{4.75} \mathrm{Cu}_{13.2}$ (atomic percent) and copper-rich phase having $74.65 \% \mathrm{Cu}, 9.20 \% \mathrm{Ni}$, and remaining elements in minor quantities. The CHEMI-STEM analysis helped identify the morphology of precipitates and relative composition of the phases that in turn determine the corrosion characteristics.

A schematic of the three phases and resulting corrosion mechanism in depicted in Fig. 7. Figure 7a shows a low magnification DFTEM image from an intra-granular region, recorded from a $\{001\}$ super-lattice reflection, corresponding to the $L 1_{2}$ phase in the [100] fcc zone axis diffraction pattern (shown as an inset in the same figure). The specific super-lattice reflection used for recording this DF image has been marked with a circle in the inset diffraction pattern. There is a high number density of fine-scale $L 1_{2}$ precipitates, highlighted in this DF image. Interestingly, there appears to be an alignment of the ordered $\mathrm{L1}_{2}$ precipitates along the $<001>\mathrm{fcc}$ direction when the TEM foil is oriented along the [001] zone axis. Such a strong alignment of the $\mathrm{L}_{1}$ precipitates was not observed when the same sample was 


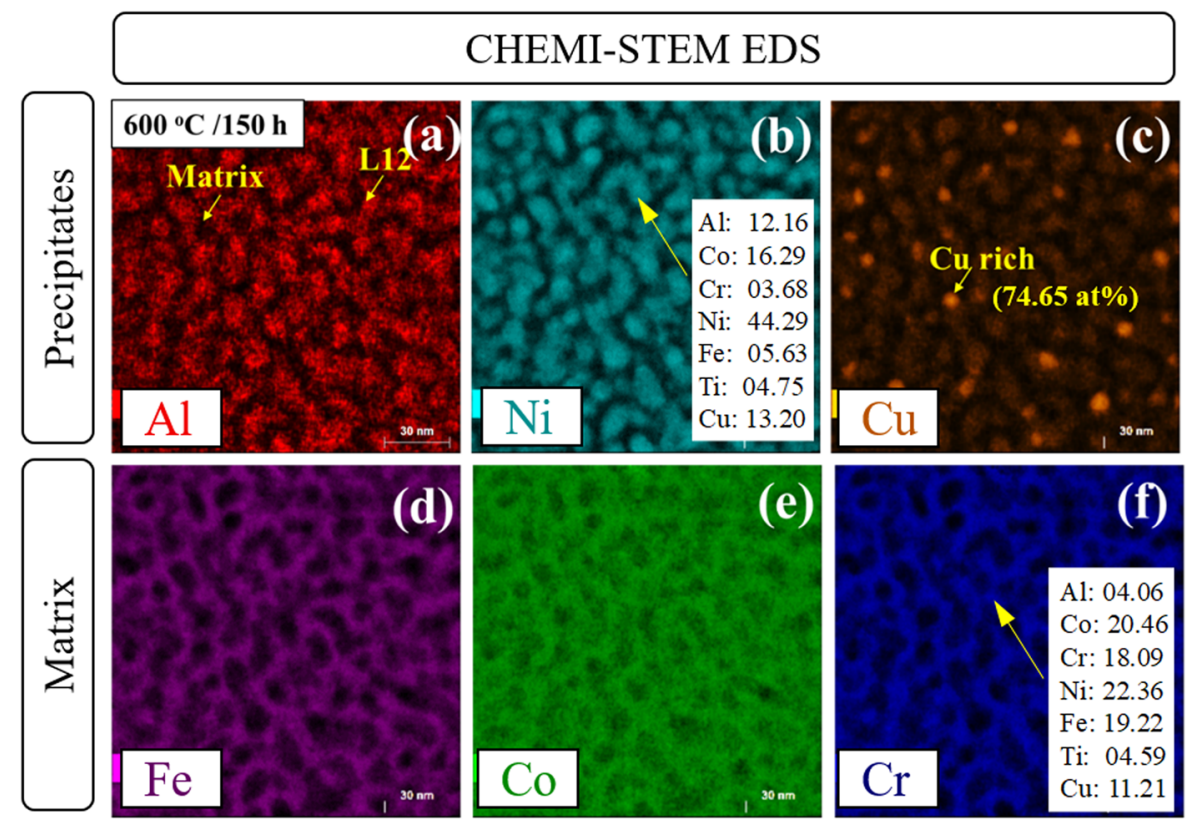

Fig. 6 Elemental maps created using CHEMI-STEM technique in the HAADF STEM mode. The elemental partitioning can be grouped into three regions: $\mathrm{L} 1_{2}$ precipitates rich in a Al-rich, $\mathbf{b} \mathrm{Ni}$-rich, and $\mathbf{c} \mathrm{Cu}$-rich clusters attached to $\mathrm{L} 1_{2}$ precipitates. The matrix is observed to be rich in d $\mathrm{Fe}$, e Co, and $\mathbf{f} \mathrm{Cr}$

imaged along other fcc zone axes. The alignment of $L 1_{2}$ precipitates along the $\langle 100\rangle$ directions, when imaged along the [001]fcc zone axis, suggests the possibility that a phase separation reaction via spinodal decomposition preceded or took place concurrently with the $\mathrm{L}_{2}$ ordering reaction. Assuming that the spinodal decomposition preceded the ordering reaction, a possible transformation pathway would be that initially the fcc phase separated into fcc 1 and fcc 2 phases. Subsequently, one of the fcc phases underwent an ordering transformation to form the $\mathrm{L}_{2}$ phase. A generalized illustration of the phases' distribution is shown in Fig. 7b, where red dots correspond to the Cu-rich clusters and long yellow cylinders to the $L 1_{2}$ phase following the SEM, TEM observations from Figs. 2, 3, and 6. In the presence of a corroding electrolyte such as $\mathrm{NaCl}$, the relative galvanic behavior of the phases comes into play between the three phases (namely, the $\mathrm{Cu}$-rich clusters, $\mathrm{L} 1_{2}$ phase, and the matrix). Galvanic coupling is also sensitive to the relative sizes of anodic and cathodic fractions, which significantly impact the corrosion mechanism. The galvanic series predicts strong anodic response of the Cu-rich phase relative to the matrix (having a composition similar to Incoloy 825). Based on the SEM/TEM findings detailed in Fig. 6, the sites of deep circular pits can be correlated to the $\mathrm{Cu}$-rich clusters that form due to strong galvanic coupling and unfavorable anode to cathode ratio. The cumulative effect of the two factors is an instantaneous onset of corrosion during potential sweep, which may explain the small current spikes seen on the anodic branch of the potentiogram. The development of the shallow periodic corrosion pattern for this sample may be explained as originating from both the matrix and the $\mathrm{L1}_{2}$ phase as illustrated in Fig. 7c. This is because of the compositional similarity between the $L 1_{2}$ phase and the surrounding matrix that sets in a relatively weak anodic response. This difference in anodic behavior between the copper-rich phase, the $L 1_{2}$ phase and the matrix ultimately results in the characteristic corroded microstructure of deep circular pits that are adjacent to elongated shallow pits as illustrated in Fig. 7d. A high magnification SEM image of the matrix is shown in Fig. 7e. While these nano-galvanic sites contribute to small corrosion current spikes on the anodic branch, a strong pitting response is at Epit from the breakdown of surface passivation.
Bulk wear and friction behavior of the HEAs are summarized in Fig. 8 and the wear volume loss and friction are quantified in Table 1c. The wear volume loss and friction coefficient were observed to increase with annealing time. The CR-R alloy had the lowest wear volume loss, followed by CR-R- 800 and CR-R- 600 , respectively. The microstructure of wear track obtained for the CR-R condition is shown in Fig. 8a. The wear track is characterized by uniform deformation and long wear scars extending through the length of the wear track. Distinct black marks seen on the wear track are metal sticking on to the wear surface originating during material transfer from the sample to the counterface and re-deposition during sliding. No debris were observed on the sides of the wear track. EDS spot scans showed negligible oxide formation on the counterface and on the wear track. An optical interferogram is shown in Fig. $8 \mathrm{~b}$ with a cross-sectional depth of $9 \mu \mathrm{m}$ at the deepest part of the wear track. The mean coefficient of friction values resolved after attaining steady state is shown in Fig. 8c. The mean friction coefficient was $0.25 \pm 0.05$. Sharp spikes were seen at the points of inflection where resistance to sliding peaked. Five friction spikes correspond to the $5 \mathrm{~Hz}$ sliding frequency. The site of these friction spikes were traced to the edge of the wear tracks where stiction renders maximum resistance to sliding. The SEM image of wear track on the CR-R-800 sample shown in Fig. $8 \mathrm{~d}$ is characterized by uniformly distributed metal-metal adhesion patches. The wear volume loss was marginally higher compared to the solutionized condition as seen from the depth of the wear track in Fig. 8e. This could be due to lower matrix hardness Fig. 8j. Friction profile was noisier compared to solutionized condition (Fig. 8c). This could be due to the friction contribution from the intermetallic particles that get dislodged and trapped between the counterface and the sample during wear. The friction varied between $0.30 \pm 0.10$ as seen in Fig. 8f. Friction from stiction at the edges of the wear track occur at same time intervals as in Fig. 8c, confirming that these indeed originated from the edges of wear track sliding at $5 \mathrm{~Hz}$ frequency. The wear morphology for the CR-R600 sample, shown in Fig. 8g, was different from the other conditions and was distinctly characterized by higher adhesion and metal-metal contact on the surface. This adhesive wear behavior of matrix is similar to that of Incoloy 825 in unidirectional sliding deformation. ${ }^{41}$ The depth of wear track was about $15 \mu \mathrm{m}$ 


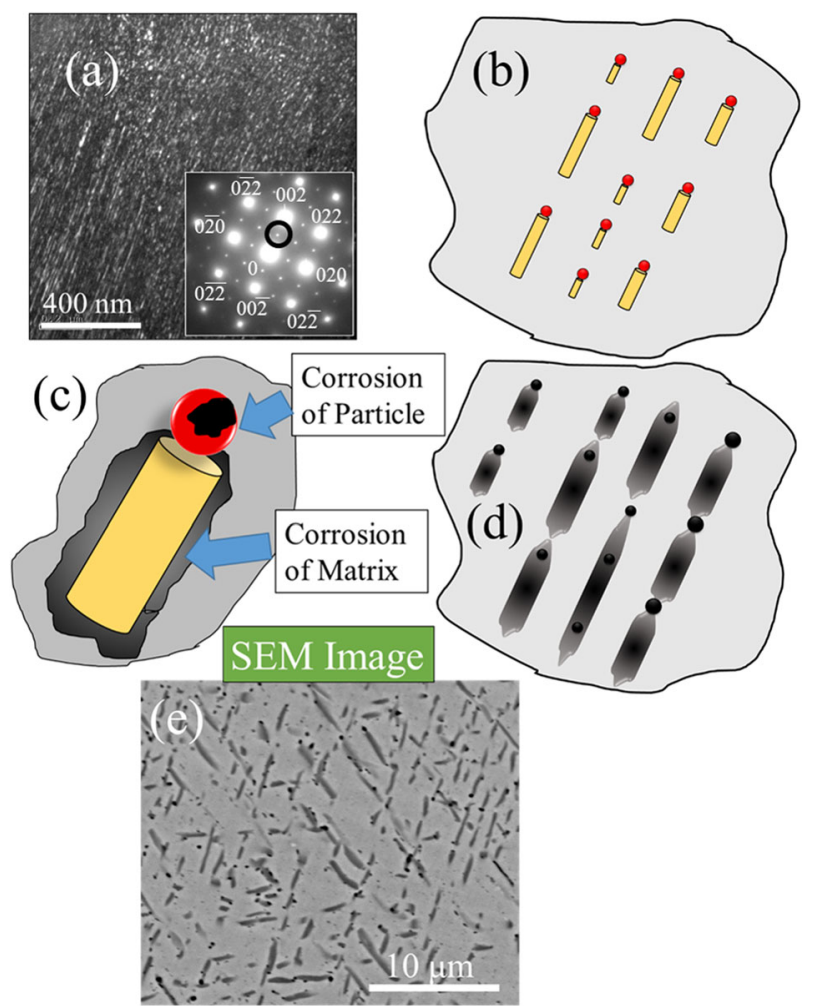

Fig. 7 a TEM from CR-R-800: DFTEM image formed using the superlattice spot highlighted in the SADP from [001]fcc shown in the inset. b Schematic showing nanometer-sized particles: $L 1_{2}$ phase shown as yellow elongated phase and Cu-rich phase with a red sphere. c Schematic of galvanic corrosion occurring on the intermetallic particles. The matrix dissolved rapidly relative to the cathodic $\mathrm{L}_{1}$ particles resulting in shallow pits and consequent dislodgement. The Cu-rich phase is relatively anodic to the matrix and corrodes faster leaving round deep pits. $\mathbf{d}$ Corrosion morphology showing long, shallow pits originating from the $\mathrm{L}_{2}$ phase and deep round pits originating from the $\mathrm{Cu}$-rich phase. e SEM image showing pits on the CR-R-800 sample

as seen from the interferogram in Fig. 8h, which corresponds to wear volume loss of $3.48 \mathrm{E}-12 \mathrm{~m}^{3}$, highest among the three conditions. Although stiction and associated friction spikes remained similar, overall sliding friction was higher and broadly distributed when compared to solutionized and CR-R-800. The phase fraction, morphology, and hardness of the secondary phase particles was higher, as well as the matrix was softer $(\sim 1 \mathrm{GPa})$, which may have resulted in excessive three-body abrasive wear. The effect of the third body trapped between the counterface and the sample may be understood by quantifying the hardness of the particles. Site-specific nano-indentation was done to evaluate the hardness of each phase in the material.

The load-displacement $(\mathrm{P}-\mathrm{d})$ curves obtained from nanoindentation technique are shown in Fig. $8 \mathrm{j}-\mathrm{I}$ and values are summarized in Table 1 . Figure $8 \mathrm{j}$, $k$ show $\mathrm{P}-\mathrm{d}$ curves from $C R-R$ and CR-R-800 conditions, respectively. The hardness values over a $500 \mu^{2}$ indentation area showed a standard deviation of about $5 \%$. This is consistent with the band of $P-d$ curves showing very small scatter in indentation depth at same indentation loads. Hardness of the CR-R-800 alloy was marginally lower compared to CR-R alloy, whereas the scatter was higher, which may be due to the higher phase fraction of secondary phase particles on the grain boundaries. There was no noticeable distinction between the morphologies of indentations between the ones that were on the matrix and on the two-phase grain boundaries. This could be due to the significantly smaller size of the secondary phase particles relative to the indentation size. The SEM images of indentations are shown as insets of respective $P-d$ curves in Fig. $8 \mathrm{j}$, k. Figure $8 \mathrm{l}$ shows the $\mathrm{P}-\mathrm{d}$ curves for CR-R-600 sample. The P-d curves show three distinct bands-labeled as R1, R2, and R3. The indentations were matched to the corresponding SEM image to correlate site-specific hardness/modulus values and indentation morphology for each phase. Indentations on the matrix phase, shown in corresponding SEM images annotated with R1, had largest size and corresponded to the R1 band on the P-d curves with a hardness of $5.73 \pm 0.56 \mathrm{GPa}$. The hardness of the matrix was significantly lower than the CR-R and CR-R-800 conditions, which may be explained from the partitioning of elements to form complex secondary phases and consequent loss in solid solution strengthening of the matrix. SEM image of the indentation on the phase mixture of $\mathrm{L}_{2}$ and matrix is annotated with R2. The indentation size was smaller compared to the ones on the matrix (R1). The hardness of the $\mathrm{L}_{2}$-matrix combination was $7.03 \pm$ $0.32 \mathrm{GPa}$ corresponding to R2 on Fig. 8l. Isolated patches of large blocky phase mixtures of $\mathrm{L1}_{2}$-Sigma showed highest hardness value of $7.44 \pm 0.13 \mathrm{GPa}$ corresponding to the R3 P-d curves, with corresponding SEM image annotated with R3. In summary, the CR$\mathrm{R}$ alloys showed pronounced solid solution strengthening, whereas prolonged heat treatments resulted in the formation of hard secondary phase precipitates. The nano-hardness results may explain the friction and surface deformation during sliding wear. The secondary phase precipitates that have high hardness may get dislodged from the matrix during sliding. The three-body wear arising from the trapped hard wear particles may have contributed to increased friction and aggravated wear loss compared to the CR-R and CR-R-800 conditions.

The $\mathrm{Al}_{0.3} \mathrm{Cu}_{0.3} \mathrm{Ti}_{0.2} \mathrm{CoCrFeNi}$ was cast and heat treated to produce a precipitation-hardened HEA. The microstructure of the alloy was extensively characterized using SEM and TEM. The cold-rolled and high-temperature-annealed (CR-R) condition exhibited mostly a single-phase solid solution structure with some fine-scale precipitation of the $\mathrm{L} 2_{1}$ phase along the grain boundary. The $\mathrm{L}_{2}$ phase precipitated at $600^{\circ} \mathrm{C}$ and $800^{\circ} \mathrm{C}$ after iso-thermal annealing. Grain boundary precipitation of $L 2_{1}$ was observed in all three conditions. These tunable microstructural features makes this HEA attractive for advanced tribocorrosion applications. The single-phase alloy showed highest corrosion resistance due to monolithic microstructure. Heat treatment introduced secondary precipitates that lowered the overall corrosion resistance due to localized dissolution of Cu-rich phase that followed the elongated $L 1_{2}$ phases and resulted in a characteristic basket-weave morphology. The single-phase alloy with higher matrix hardness showed better wear resistance and lower friction values. The wear resistance decreased with increasing secondary phase fraction and the dislodged intermetallic particles contributed to aggressive wear from three-body abrasion.

\section{METHODS}

Alloy with nominal composition of $\mathrm{Al}_{0.3} \mathrm{Cu}_{0.3} \mathrm{Ti}_{0.2} \mathrm{CoCrFeNi}$ was prepared by arc-melting high-purity constituent elements. The ingots were re-melted five times for homogenization. Microstructural characterization was performed using SEM (FEI Nova-NanoSEM $230^{\mathrm{TM}}$ ), coupled with EDS. TEM studies were carried out using FEl Tecnai G2 TF20 ${ }^{\mathrm{TM}}$ operating at $200 \mathrm{kV}$. Precipitate characterization was done using conventional and high-angle annular DF-scanning TEM (HAADF STEM) mode. EDS (Super-X system) equipped on an FEI-TITAN G2 TEM microscope was utilized in the HAADF STEM mode operating at $300 \mathrm{kV}$ to measure the composition and the results were analyzed with FEI's ES vision software version 6. An FEI Nova Nanolab 200 dual-beam focused ion beam using $\mathrm{Ga}^{+}$beam was used for preparing TEM foils. Ion beam thinning of the samples was done in 

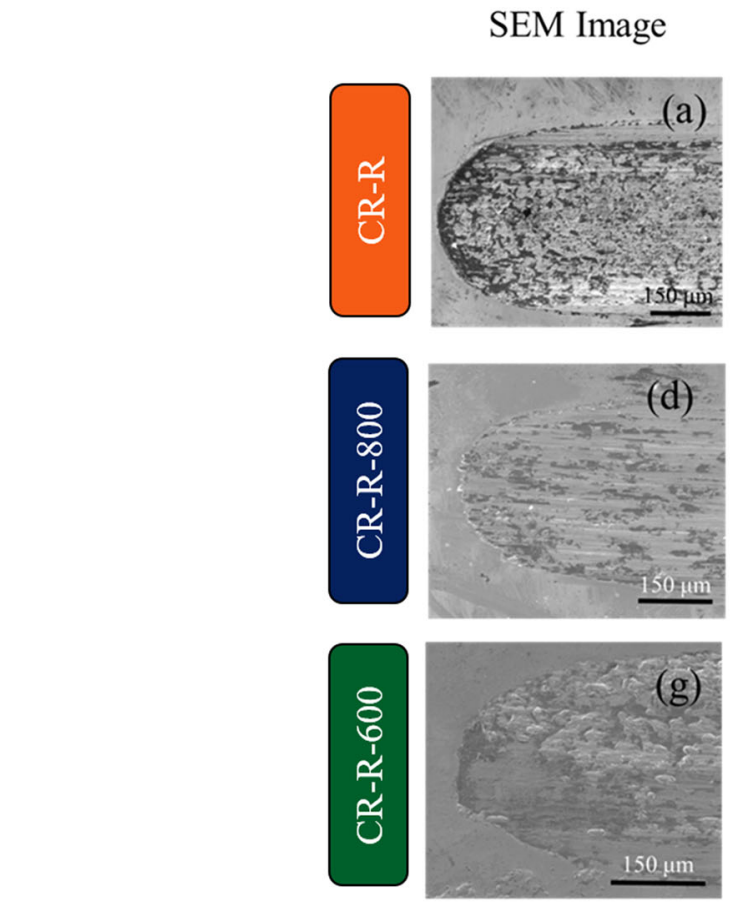

3D Interferogram
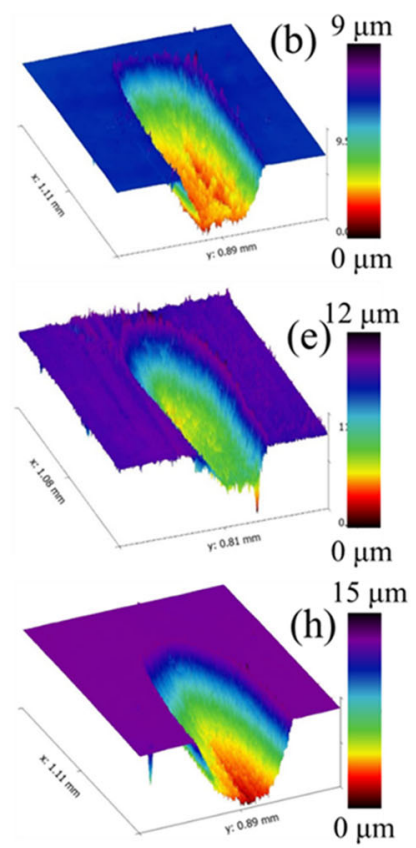

Friction Coefficient
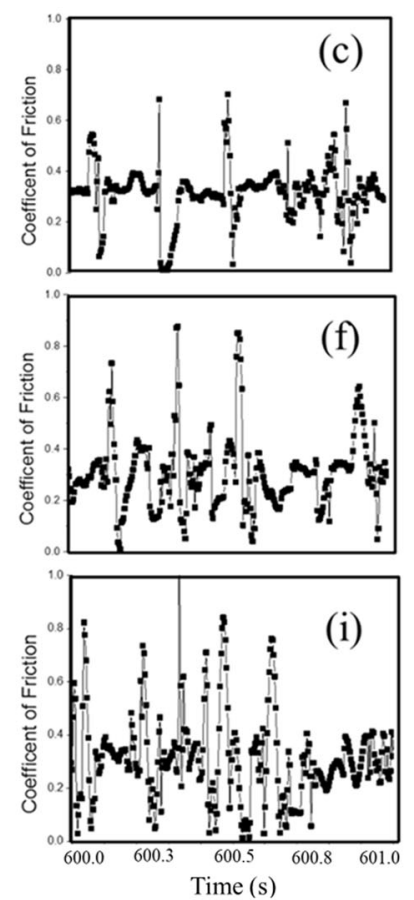
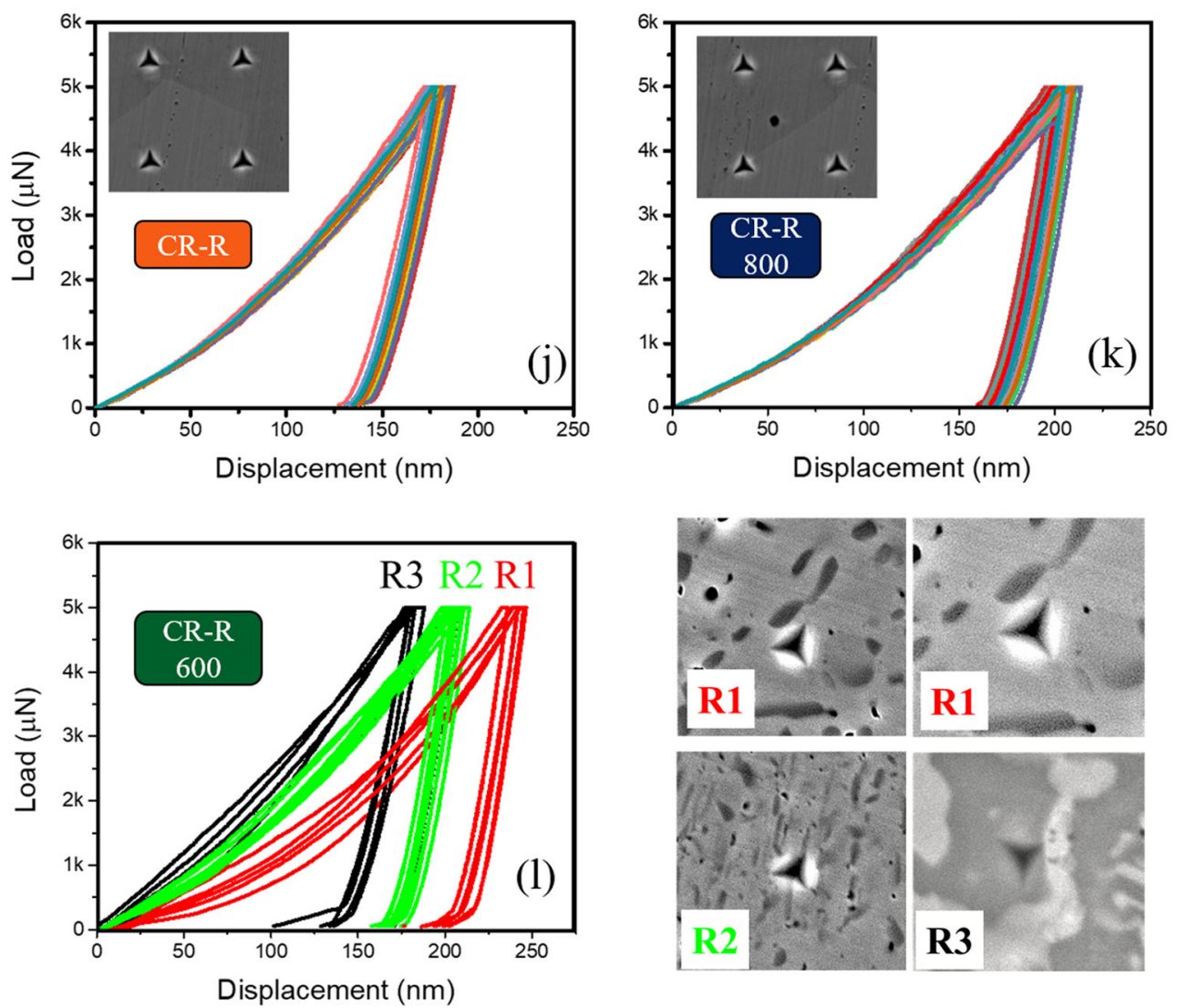

Fig. 8 a SEM image of a wear track of solutionized alloy, CR-R; $\mathbf{b}$ interferogram showing depth of wear track, and $\mathbf{c}$ friction coefficient averaging at 0.3. $\mathbf{d}$ SEM image of wear track on the CR-R-800, e interferogram of wear track, and f friction coefficient for CR-R-800. $\mathbf{g}$ SEM image of the wear track on the CR-R-600. $\mathbf{h}$ White light interferogram showing the wear track depth. $\mathbf{i}$ Friction profile for the CR-R 600 sample. Load-displacement curves from the nano-indentation for: $\mathbf{j}$ the single-phase fcc alloy (CR-R) along with the SEM image of the indentations shown in the inset, $\mathbf{k}$ the CR-R-800 alloy showing SEM images of the indents in the inset, and I the CR-R-600 alloy. SEM images of indentations on the matrix are annotated as $\mathrm{R} 1$, on the matrix and $\mathrm{L} 1_{2}$ phase mixture as $\mathrm{R} 2,+$ and on the sigma phase as $\mathrm{R} 3$ 
multiple steps starting with $30 \mathrm{kV}$ ions and finishing with $5 \mathrm{kV}$ ions to reduce surface damage caused by high-energy ions.

Corrosion behavior of the alloys was evaluated in $3.5 \mathrm{wt} \% \mathrm{NaCl}$ solution (Alfa Chemicals) after polishing to 1200 grit. A three-electrode cell with saturated calomel as reference $(-253 \mathrm{mV}$ vs. SHE), high-density graphite as counter, and samples as working electrode were connected to Gamry Ref 3000 Potentiostat. The samples were immersed in the electrolyte in excess of $10 \mathrm{~h}$ to observe fluctuations in the OCP. After attaining equilibrium, with a stable OCP (fluctuations $<5 \mathrm{mV} / \mathrm{s}$ ), the samples were swept with a scan rate of $0.16 \mathrm{mV} / \mathrm{s}$ from $-250 \mathrm{mV}$ with respect to OCP to a current density of $10-{ }^{5} \mathrm{amps} / \mathrm{cm}^{2}$.

Wear performance was evaluated using Rtec Universal Tribometer. A 3 $\mathrm{mm} \mathrm{Si} \mathrm{N}_{4}$ ball was used as the counterface material. Samples were cut to $10 \mathrm{~mm} \times 10 \mathrm{~mm} \times 5 \mathrm{~mm}$ dimensions, polished to $1200 \mathrm{grit}$, and cleaned with alcohol to remove oil-based polishing residues from the surface. Sliding reciprocating wear tests were performed under a normal load of $5 \mathrm{~N}$ and a sliding frequency of $5 \mathrm{~Hz}$ for $20 \mathrm{~min}$. The wear tracks were scanned using white light interferometry. Gwyddion image processing software was used to generate isometric views of the wear tracks and interferograms were processed to quantify wear volume loss.

Nano-indentation (Hysitron Inc., Minneapolis, MN, USA) was performed at room temperature using a diamond Berkovich tip. The indentation was carried out at $5000 \mu \mathrm{N}$ load with a loading time of $5 \mathrm{~s}$, holding time of $2 \mathrm{~s}$, and unloading time of $5 \mathrm{~s}$. Ten micrometers of spacing between indents was used to avoid overlap of plastic zones from adjacent indents. A large number of indents were made in the form of square matrices to ensure multiple indents on each phase. The indentations were observed in SEM and phase-specific hardness-modulus data were extracted from the P-d curves.

\section{DATA AVAILABILITY}

The data that support the findings of this study are available within the paper. Any further information or clarification is available from the corresponding author upon reasonable request.

\section{ACKNOWLEDGEMENTS}

We acknowledge the Materials Research Facility (MRF) at the University of North Texas for use of microscopy and atom probe tomography facilities, and the Center for Electron Microscopy and Analysis (CEMAS) at the Ohio State University for microscopy facilities.

\section{AUTHOR CONTRIBUTIONS}

A.V.A. performed corrosion and wear experiments, microscopy of corroded and wear samples, and data analysis; B.G. cast and processed the materials, performed SEM, TEM characterization; Sa.M. conducted nano-indentation experiments. Su.M. and R.B. supervised the work. All the authors discussed and contributed to the writing of the manuscript.

\section{ADDITIONAL INFORMATION}

Competing interests: The authors declare no competing interests.

Publisher's note: Springer Nature remains neutral with regard to jurisdictional claims in published maps and institutional affiliations.

\section{REFERENCES}

1. Gludovatz, B. et al. A fracture-resistant high-entropy alloy for cryogenic applications. Science. (NY) 345, 1153-1158 (2014).

2. Miracle, D. \& Senkov, O. A critical review of high entropy alloys and related concepts. Acta Mater. 122, 448-511 (2017).

3. Ye, Y., Wang, Q., Lu, J., Liu, C. \& Yang, Y. High-entropy alloy: challenges and prospects. Mater. Today 19, 349-362 (2016).

4. Tsai, M. \& Yeh, J. High-entropy alloys: a critical review. Mater. Res. Lett. 2, 107-123 (2014).

5. Xia, S., Zhen, W., Yang, T. \& Zhang, Y. Irradiation behavior in high entropy alloys. J. Iron Steel Res. Int. 22, 879-884 (2015).

6. Xia, S., Yang, X., Yang, T., Liu, S. \& Zhang, Y. Irradiation resistance in AlxCoCrFeNi high entropy alloys. JOM 67, 2340-2344 (2015).
7. Liu, Y. et al. Oxidation behavior of high-entropy alloys AlxCoCrFeNi $(x=0.15,0.4)$ in supercritical water and comparison with HR3C steel. Trans. Nonferrous Met. Soc. China 25, 1341-1351 (2015).

8. Holcomb, G. R., Tylczak, J. \& Carney, C. Oxidation of CoCrFeMnNi high entropy alloys. JOM 67, 2326-2339 (2015).

9. Grewal, H. S. et al. Activation energy and high temperature oxidation behavior of multi-principal element alloy. Adv. Eng. Mater. 19, (2017).

10. Ayyagari, A. et al. Reciprocating sliding wear behavior of high entropy alloys in dry and marine environments. Mater. Chem. Phys. 162-169 (2017).

11. Gwalani, B. et al. Microstructure and wear resistance of an intermetallic-based Al0. 25Ti0. 75CoCrFeNi high entropy alloy. Mater. Chem. Phys. 197-206 (2017).

12. Poletti, M. G., Fiore, G., Gili, F., Mangherini, D. \& Battezzati, L. Development of a new high entropy alloy for wear resistance: FeCoCrNiW 0.3 and FeCoCrNiW 0.3 5at.\% of C. Mater. Des. 115, 247-254 (2017).

13. Poulia, A., Georgatis, E., Lekatou, A. \& Karantzalis, A. Microstructure and wear behavior of a refractory high entropy alloy. Int. J. Refract. Met. Hard Mater. 57, 50-63 (2016).

14. Poulia, A., Georgatis, E., Lekatou, A. \& Karantzalis, A. Dry-sliding wear response of MoTaWNbV high entropy alloy. Adv. Eng. Mater. 19, 1600535 (2016).

15. Tian, L., Xiong, W., Liu, C., Lu, S. \& Fu, M. Microstructure and wear behavior of atmospheric plasma-sprayed AlCoCrFeNiTi high-entropy alloy coating. J. Mater. Eng. Perform. 25, 5513-5521 (2016).

16. Huo, W., Shi, H., Ren, X. \& Zhang, J. Microstructure and wear behavior of $\mathrm{CoCr}$ FeMnNbNi high-entropy alloy coating by TIG cladding. Adv. Mater. Sci. Eng. 2015 (2015).

17. Qiu, Y., Thomas, S., Gibson, M. A., Fraser, H. L. \& Birbilis, N. Corrosion of high entropy alloys. npj Mater Degrad 1, 15 (2017).

18. Li, B. et al. Structure and properties of FeCoNiCrCu0. 5Alx high-entropy alloy. Trans. Nonferrous Met. Soc. China 23, 735-741 (2013).

19. Qiu, Y., Gibson, M., Fraser, H. \& Birbilis, N. Corrosion characteristics of high entropy alloys. Mater. Sci. Technol. 31, 1235-1243 (2015).

20. Ren, B. et al. Corrosion behavior of $\mathrm{CuCrFeNiMn} \mathrm{high} \mathrm{entropy} \mathrm{alloy} \mathrm{system} \mathrm{in} 1 \mathrm{M}$ sulfuric acid solution. Mater. Corros. 63, 828-834 (2012).

21. Shi, Y. et al. Corrosion of AlxCoCrFeNi high-entropy alloys: Al-content and potential scan-rate dependent pitting behavior. Corros. Sci. 119, 33-45 (2017).

22. Nair, R. et al. Exceptionally high cavitation erosion and corrosion resistance of a high entropy alloy. Ultrason. Sonochem. 41, 252-260 (2018).

23. Nair, R. et al. Slurry erosion behavior of high entropy alloys. Wear 386, 230-238 (2017).

24. Nair, R. B., Arora, H. S., Ayyagari, A., Mukherjee, S. \& Grewal, H. S. High entropy alloys: prospective materials for tribo-corrosion applications. Adv. Eng. Mater. 20, 1700946.

25. Wani, l. et al. Ultrafine-grained AlCoCrFeNi2. 1 Eutectic high-entropy alloy. Mater. Res. Lett. 4, 174-179 (2016).

26. Bhattacharjee, T. et al. Simultaneous strength-ductility enhancement of a nanolamellar AICoCrFeNi 2.1 Eutectic high entropy alloy by cryo-rolling and annealing. Sci. Rep. 8, 3276 (2018)

27. Gao, X. et al. Microstructural origins of high strength and high ductility in an AlCoCrFeNi2. 1 Eutectic high-entropy alloy. Acta Mater. 141, 59-66 (2017).

28. Lu, Y. et al. A promising new class of high-temperature alloys: eutectic highentropy alloys. Sci. Rep. 4, 6200 (2014).

29. Pohan, R. M. et al Microstructures and mechanical properties of mechanically alloyed and spark plasma sintered Al0. 3CoCrFeMnNi high entropy alloy. Mater. Chem. Phys. 210, 62-70 (2017).

30. Borkar, T. et al. Hierarchical multi-scale microstructural evolution in an as-cast Al2CuCrFeNi2 complex concentrated alloy. Intermetallics 71, 31-42 (2016).

31. Gwalani, B. et al. Modifying transformation pathways in high entropy alloys or complex concentrated alloys via thermo-mechanical processing. Acta Mater. 153, 169-185 (2018).

32. Gwalani, B. et al. Optimizing the coupled effects of Hall-Petch and precipitation strengthening in a Al0. 3CoCrFeNi high entropy alloy. Mater. Des. 121, 254-260 (2017).

33. Gwalani, B. et al. Stability of ordered L12 and B2 precipitates in face centered cubic based high entropy alloys-AI0. 3CoFeCrNi and Al0. 3CuFeCrNi2. Scr. Mater. 123, 130-134 (2016).

34. Aditya, A., Subramanian, P., Krishna, V. G. \& Babu, U. C. Influence of rolling path on microstructure and mechanical properties in EB refined tantalum. Trans. Indian Inst. Met. 65, 435-442 (2012).

35. Obayi, C. S. et al. Influence of cross-rolling on the micro-texture and biodegradation of pure iron as biodegradable material for medical implants. Acta Biomater. 17, 68-77 (2015)

36. Bharat, G. et al. Role of copper on L12 precipitation strengthened fcc based high entropy alloy. Under Review (2018).

37. Pistorius, P. \& Burstein, G. Growth of corrosion pits on stainless steel in chloride solution containing dilute sulphate. Corros. Sci. 33, 1885-1897 (1992). 
38. Pistorius, P. \& Burstein, G. Aspects of the effects of electrolyte composition on the occurrence of metastable pitting on stainless steel. Corros. Sci. 36, 525-538 (1994).

39. Tian, W., Du, N., Li, S., Chen, S. \& Wu, Q. Metastable pitting corrosion of 304 stainless steel in 3.5\% NaCl solution. Corros. Sci. 85, 372-379 (2014).

40. Tang, Y. et al. The metastable pitting potential and its relation to the pitting potential for four materials in chloride solutions. Corros. Sci. 80, 111-119 (2014).

41. Thakur, A., Mohanty, A., Gangopadhyay, S. \& Maity, K. Tool wear and chip characteristics during dry turning of Inconel 825. Proc. Mater. Sci. 5, 2169-2177 (2014). Attribution 4.0 International License, which permits use, sharing, adaptation, distribution and reproduction in any medium or format, as long as you give appropriate credit to the original author(s) and the source, provide a link to the Creative Commons license, and indicate if changes were made. The images or other third party material in this article are included in the article's Creative Commons license, unless indicated otherwise in a credit line to the material. If material is not included in the article's Creative Commons license and your intended use is not permitted by statutory regulation or exceeds the permitted use, you will need to obtain permission directly from the copyright holder. To view a copy of this license, visit http://creativecommons. org/licenses/by/4.0/.

(c) The Author(s) 2018 